\section{Journal of}

Gastroenterology
GE Port J Gastroenterol 2023;30:162-165

DOI: $10.1159 / 000520273$
Received: July 7, 2021

Accepted: October 5, 2021

Published online: November 24, 2021

\title{
SX-ELLA Danis-Stent for Refractory Acute Esophageal Variceal Bleeding
}

\author{
Pedro Currais ${ }^{a, b}$ Gonçalo Nunes $^{b, d}$ Marta Patita $^{b}$ Élia Coimbra ${ }^{c}$ \\ Jorge Fonseca ${ }^{b, d}$ \\ ${ }^{a}$ Gastroenterology Department, Instituto Português de Oncologia de Lisboa, Lisbon, Portugal; b Gastroenterology \\ Department, Hospital Garcia de Orta, Almada, Portugal; ' Interventional Radiology Unit, Hospital Curry Cabral,

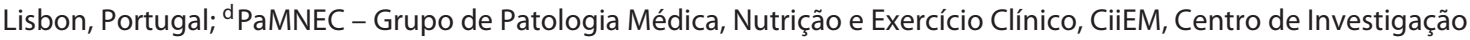 \\ Interdisciplinar Egas Moniz, Monte da Caparica, Portugal
}

\section{Keywords}

Danis-stent · Upper gastrointestinal bleeding · Esophageal varices

\section{Prótese Danis na hemorragia aguda refratária de varizes esofágicas}

\section{Palavras Chave}

Prótese Danis · Hemorragia digestiva alta $\cdot$ Varizes esofágicas

The authors describe a 78-year-old male with alcoholic liver cirrhosis (Child-Pugh score 9 points, Meld-Na 16 points, without active drinking habits for several years). The patient had clinically significant portal hypertension manifested as refractory ascites managed with repeated large volume paracentesis and five bleeding episodes from esophageal varices. During these bleeding events the patient was treated with multiple sessions of band ligation and sclerotherapy. Two days after being discharged from the hospital due to the last bleed- ing episode he was readmitted due to hematemesis with hypotension and anemia. After clinical stabilization and blood transfusion to reach safe hemoglobin levels (hemoglobin at admission: $\mathrm{Hb} 6.7 \mathrm{~g} / \mathrm{dL}$ ), upper GI endoscopy was performed, showing in the distal third of the esophagus (37 cm from the incisors), an esophageal varix with cherry-red spots and a white nipple sign suggestive of a rupture point (Fig. 1a). Band ligation was initially tried, which was not successful due to marked fibrosis that prevented the cord to enter in the cap for banding. A massive variceal bleeding developed causing loss of endoscopic view and an SX-ELLA Danis-stent (25 $\times 135 \mathrm{~mm}$, fully covered) was placed under guidewire with immediate technical and clinical success (Fig. 1b). The proximal limit of SX-ELLA Danis-stent was located at $29 \mathrm{~cm}$ of the incisors. The patient progressed favorably with no evidence of further blood loss and ICU admission was not needed. Given the several episodes of variceal bleeding despite endoscopic therapy and refractory ascites, 7 days after the index procedure a Transhepatic Portosystemic Shunt (TIPS) VIATORR ${ }^{\circledR}$ endoprosthesis with $7 \mathrm{~mm}$ was placed without complications reaching a karger@karger.com www.karger.com/pjg

Karger $\stackrel{\text { ' }}{5}$ BOPEN ACCESS (c) 2021 Sociedade Portuguesa de Gastrenterologia. Published by S. Karger AG, Basel

This is an Open Access article licensed under the Creative Commons Attribution-NonCommercial-4.0 International License (CC BY-NC) (http://www.karger.com/Services/OpenAccessLicense), applicable to the online version of the article only. Usage and distribution for commercial purposes requires written permission.
Correspondence to:

Pedro Currais, pedro_currais@live.com.pt 

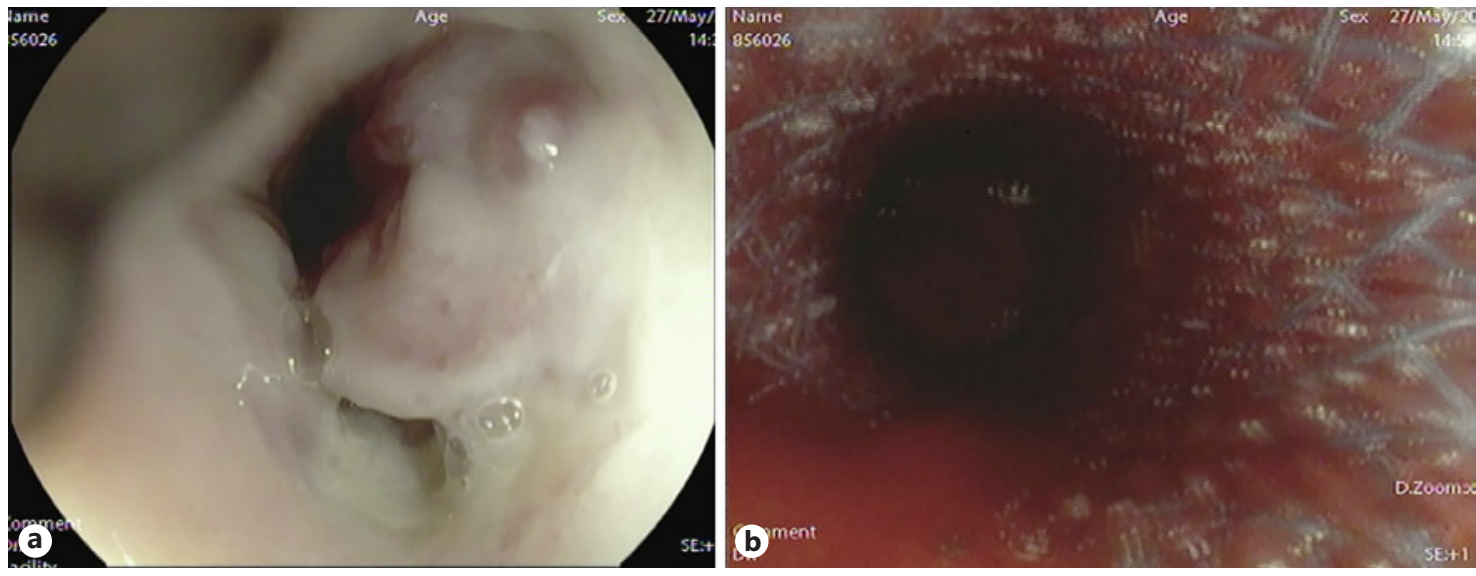

Fig. 1. EGD showing an esophageal varix cord with a nipple sign compatible with a rupture point (a). Massive bleeding after unsuccessful band ligation managed with the placement of an SX-ELLA Danis-stent (b).

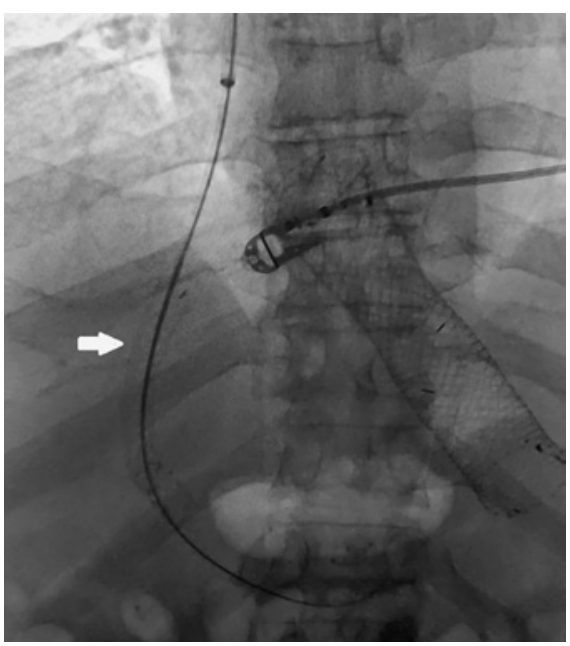

Fig. 2. TIPS was placed without immediate complications. VIATORR endoprosthesis with 8-10 mm was used. TIPS (white arrow) and SX-ELLA Danis-stent seen on X-ray.
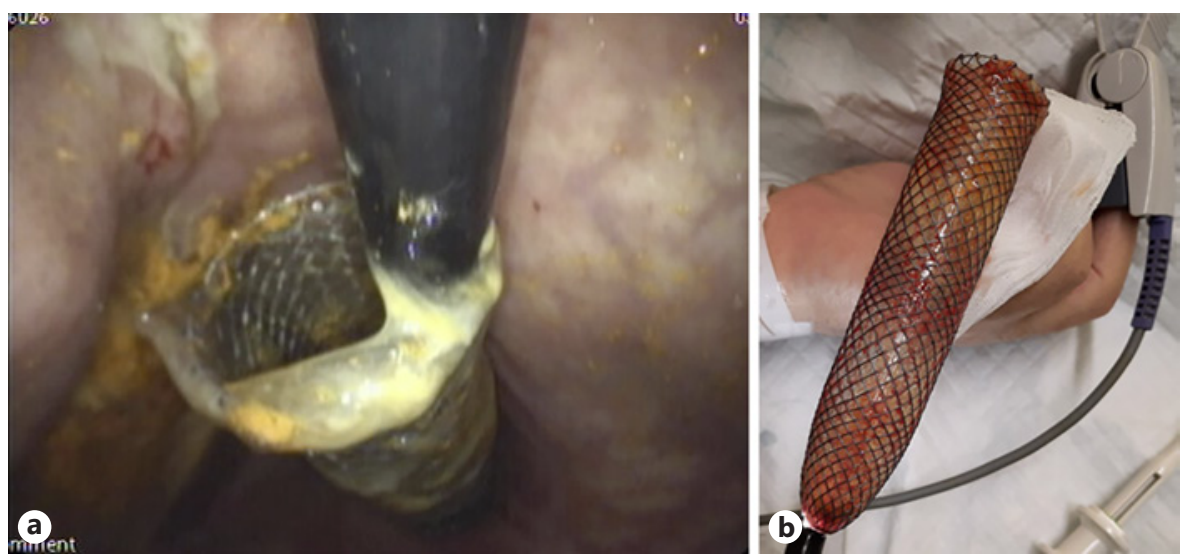

Fig. 3. SX-ELLA Danis-stent seen endoscopically in retroflexion (a). The stent was removed using a foreign body forceps without complications (b). hepatic venous pressure gradient of $11 \mathrm{~mm} \mathrm{Hg}$ (from an initial $22 \mathrm{~mm} \mathrm{Hg}$ ) (Fig. 2). The Danis-stent was endoscopically removed using a foreign body forceps 11 days after its placement (Fig. 3). A marked reduction in the size of the esophageal varices and a whitish scarry area in the distal esophagus coincident with the previous rupture point were observed (Fig. 4). Clinical evolution was favorable with no further bleeding recurrence or hepatic encephalopathy and partial improvement of ascites. The patient was discharged and maintained follow-up on hepatology outpatient clinic.

SX-Ella Danis-Stent for Variceal Bleeding

\section{Discussion}

Portal hypertension is the hemodynamic abnormality associated with the most severe complications of liver cirrhosis, including ascites, hepatic encephalopathy, and bleeding from gastroesophageal varices. Variceal bleeding is a medical emergency associated with a mortality of $10-20 \%$ in 6 weeks [1].

The combination of vasoactive drugs and endoscopic therapy (preferably esophageal band ligation) are recommended as the main therapeutic modality for bleeding 

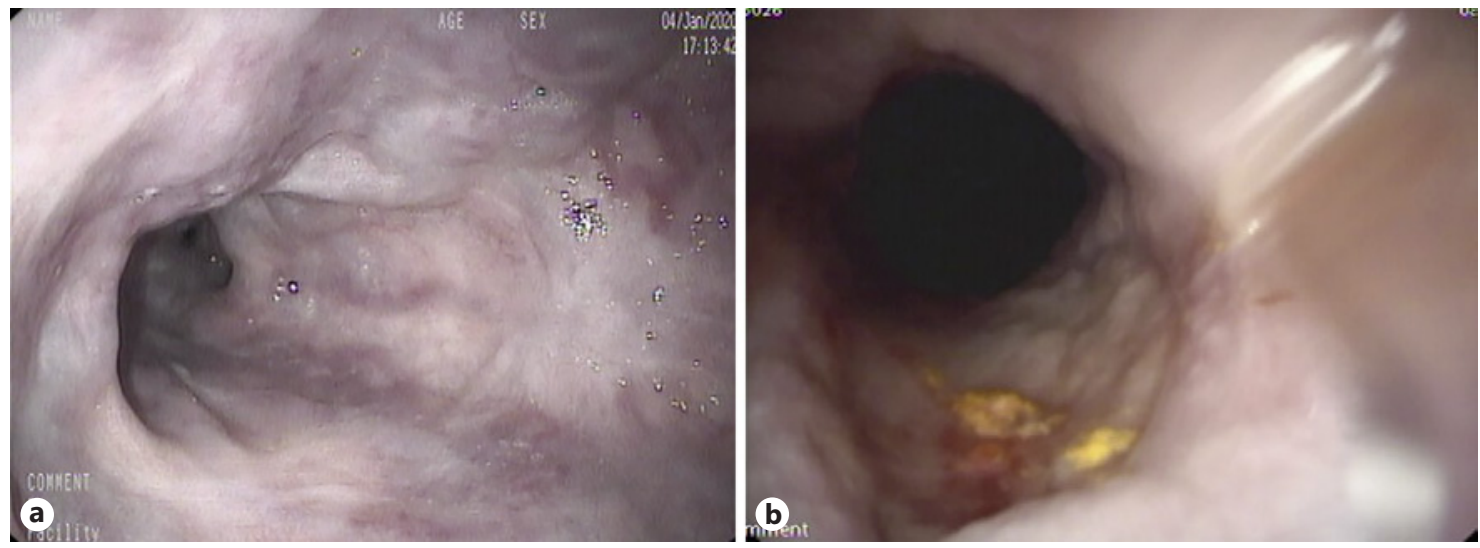

Fig. 4. EGD after stent removal showing an important reduction in esophageal varix size (a). On the distal esophagus a whitish scarry area, in relation with the previous rupture point, was also seen (b).

esophageal varices; however, it can be challenging in the presence of massive bleeding. In this scenario, as expressed in AASLD and EASL recommendations, fully covered self-expandable metallic stents and SengstakenBlakemore tubes (SBT) are viable options, recommended as bridge to a definitive therapy [1-3].

SBT are the most widely used, providing bleeding controls of $90 \%$. However, it should only be used under intensive care facilities due to the high risk of severe and life-threatening complications. Dedicated fully covered self-expandable metallic stents (like SX-ELLA Danisstent) have also been used in this setting, achieving an higher rate of bleeding control with a lower incidence of severe complications $[4,5]$. In this clinical case the authors exemplify the use of an SX-ELLA Danis-stent as bridge for TIPS placement in a patient with massive variceal bleeding refractory to band ligation.

From the authors' point of view, SX-ELLA Danisstents should generally be favored over SBT placement due to its higher efficacy, less potential complications, and the fact that it can be used by endoscopists in a urgent setting even by those without experience in fluoroscopy. Also, as Danis-stent allows an immediate control of variceal bleeding, it will reduce the time needed for airway protection and ICU admission. Nevertheless, all emergency physicians should be able do use SBT and therefore it will retain its role in a facility without gastroenterology support and in all cases of uncontrolled bleeding from gastric varices where Danis-stent placement would not be effective.

\section{Statement of Ethics}

The authors declare that all ethical procedures were followed. The patient signed written consent, allowing use and divulgation of clinical information and images.

\section{Conflict of Interest Statement}

The authors have no conflicts of interest to declare. Moreover, they are aware that the manuscript's copyright belongs to GE Portuguese Journal of Gastroenterology.

\section{Funding Sources}

No funding resources were used in the elaboration of the article.

\section{Author Contributions}

Gonçalo Nunes - patient evaluation, clinical data collection and performed the endoscopic procedure; Marta Patita - patient evaluation and clinical data collection; Élia Coimbra - performed the TIPS placement and gave these figures for publication; Pedro Currais - manuscript draft; Gonçalo Nunes and Jorge Fonseca critical review of the manuscript.

\section{Data Availability Statement}

All the data and exams related to this clinical case are available on Hospital Garcia de Orta informatic system. 


\section{References}

1 de Franchis R; Baveno VI Faculty. Expanding consensus in portal hypertension: Report of the Baveno VI Consensus Workshop: Stratifying risk and individualizing care for portal hypertension. J Hepatol. 2015 Sep;63(3):74352.

2 Angeli P, Bernardi M, Villanueva C, Francoz C, Mookerjee RP, Trebicka J, et al.; European Association for the Study of the Liver. Electronic address: easloffice@easloffice.eu; European Association for the Study of the Liver.
EASL Clinical Practice Guidelines for the management of patients with decompensated cirrhosis. J Hepatol. 2018 Aug;69(2):406-60.

3 Garcia-Tsao G, Abraldes JG, Berzigotti A, Bosch J. Portal hypertensive bleeding in cirrhosis: Risk stratification, diagnosis, and management: 2016 practice guidance by the American Association for the study of liver diseases. Hepatology. 2017 Jan;65(1):310-35.

4 Escorsell À, Pavel O, Cárdenas A, Morillas R, Llop E, Villanueva C, et al.; Variceal Bleeding
Study Group. Esophageal balloon tamponade versus esophageal stent in controlling acute refractory variceal bleeding: A multicenter randomized, controlled trial. Hepatology. 2016 Jun;63(6):1957-67.

5 Pfisterer N, Riedl F, Pachofszky T, Gschwantler M, König K, Schuster B, et al. Outcomes after placement of a SX-ELLA oesophageal stent for refractory variceal bleeding - A national multicentre study. Liver Int. $2019 \mathrm{Feb} ; 39(2): 290-8$. 